\title{
Design and Construction of Equipment to Make Adsorption at Pilot Plant Scale of Heavy Metals
}

\author{
Juan C. Moreno-Piraján ${ }^{\mathrm{a}}$, David Rangel ${ }^{\mathrm{b}}$, Bibiana Amaya ${ }^{\mathrm{b}}$, Edgar M. Vargas ${ }^{\mathrm{b}}$, \\ and Liliana Giraldo ${ }^{\mathrm{c}}$ \\ ${ }^{a}$ Departamento de Química, Facultad de Ciencias, Universidad de Los Andes, Grupo de \\ Investigación en Sólidos Porosos y Calorimetría, Carrera 1 No. 18A-10/70, Bogotá, Colombia \\ b Departamento de Ingeniería Química, Facultad de Ingeniería, Universidad de Los Andes, \\ Carrera 1 No. 18A-10/70, Bogotá, Colombia \\ ${ }^{c}$ Departamento de Química, Universidad Nacional de Colombia, Carrera 30 calle 45, Bogotá, \\ Colombia
}

Reprint requests to Prof. J. C. M.-P.; E-mail: jumoreno@uniandes.edu.co

Z. Naturforsch. 63a, 453 - 461 (2008); received November 29, 2006

\begin{abstract}
The purpose of this paper was to illustrate the procedure to obtain activated carbon from lignocellulosic residues through chemical and physical paths. A general surface characterization was made and aqueous solution isotherms were obtained in order to evaluate the behaviour of each carbon atom in solutions contaminated with selective ions. The other purpose was to show a simple way to perform a scale-up process of an absorber from the laboratory level to an industrial level, using the breaking curves in fixed beds developed through the continuous pursuit of the $\mathrm{Pb}$ (II) and $\mathrm{Cr}(\mathrm{VI})$ ions concentration in the effluent of the bed. Activated carbon was used to study the adsorption of $\mathrm{Pb}$ (II) and $\mathrm{Cr}(\mathrm{VI})$. Isotherms of aqueous adsorption were determined. This model was developed in order to examine its efficiency and to compare it with an experimental model made in the laboratory, which rendered very similar results. The main characteristic of the feasibility of the application of this design is the fact that neither tedious calculations nor mass transfer coefficients are required in order to construct the above-mentioned curves. The model was developed by applying concepts such as mass transfer zone (MTZ) and length of unused bed (LUB), which are the dynamical basis understanding for the adsorption process in fixed beds.

As a complementary item of the experiment, within a pilot plant scale, a filter was developed in order to achieve flexibility when manipulating the most important adsorption parameters and to enable the control of the variables involved in the process that change the operating conditions.
\end{abstract}

Key words: Activated Carbon; Mass Transfer Zone; Length of Unused Bed; Curve of Breakthrough.

\section{Introduction}

Due to the increasing level of toxic metals found in residual streams originating from industrial discharges, new methods and techniques are developed for environmental control. Metal adsorption by porous solids is one of the most useful options for this type of problems.

Even though several publications have reported on water treatment in batch systems, nowadays continuous columns perform the treatment with fixed beds because of the rapid process that takes place. To optimize the process, it is necessary to perform scale-up studies that can be used for industrial equipments, owing to the dynamical behaviour, that can be described in terms of time-concentration profiles commonly called breaking curves.
The construction of a breaking curve is based on the concentration pursuit that can be emptied into the effluent $(C)$ while a contaminated influent with a known concentration $\left(C_{0}\right)$ is continuously poured into the fixed bed absorber. The characteristic shape of this curve will depend on the balance between the solid and the liquid phase, based on the kinetic adsorption process, which is divided into four phenomena: (i) diffusion in the bulk fluid, (ii) external mass transfer, (iii) interparticular mass transfer and (iv) micropore adsorption $[1-3]$.

During the first period, the contaminant concentration in the final part of the bed is practically zero, however, as time goes on and the contaminated influent is continuously fed in, a limit concentration is reached, which is known as breaking point $\left(C_{\mathrm{b}}\right)$ at the time $\left(t_{\mathrm{b}}\right)$. In high-level processes this point will determine the 
moment in which the feed has to be interrupted for determining the bed and deviating to a new or fresh one, in order to maintain the process while the adsorbent material is renewed [2]. If the feed into the absorber is not interrupted, the concentration that appears in the effluent after the breaking point starts to increase rapidly until the concentration ratio $C / C_{0}$ equals to 1 is achieved.

Mathematical models to predict the breaking curves are summarized in [4-7]. But, due to its intricate complexity and difficulty in the determination of some of the parameters and calculations, it is preferable to make an analysis of the operation in a fixed bed, based on experimental data.

By means of the application of concepts as mass transfer zone (MTZ) and length of unused bed (LUB) the scale-up of the process to a major length filter was possible and, therefore, a new curve of the scaled model was obtained. A theoretical development of the problem was made and experimental procedures confirmed that the mathematical model actually describes the phenomenon in a fixed bed of an adsorbent.

\section{Experimental}

\subsection{Previous Treatment of the Initial Material}

The particles of the initial materials (sugar cane husk and wood sawdust) were sieved for an average particle diameter of $0.551 \mathrm{~mm}$ ( -30 to +50 US nets). Afterwards, the materials were washed several times with distilled water and dried for $24 \mathrm{~h}$ in a furnace at $90{ }^{\circ} \mathrm{C}$. Finally, the materials were stored in closed, dry plastic packages.

\subsection{Obtaining Activated Carbon by Chemical and Physical Activation}

The sugar cane husk (CAB) and the wood sawdust (CAA) were pyrolyzed at $973 \mathrm{~K}$ for $2 \mathrm{~h}$ under $\mathrm{N}_{2}$ flow $(100 \mathrm{~mL} / \mathrm{min})$. The obtained chars were milled and sieved for a particle size of $0.2-0.3 \mathrm{~mm}$. Then they were placed under a $200 \mathrm{~mL} / \mathrm{min}$ flow of $\mathrm{CO}_{2}$ at $1173 \mathrm{~K}$ during $4 \mathrm{~h}$.

For chemical activation, $\mathrm{H}_{3} \mathrm{PO}_{4}(65 \% \mathrm{v} / \mathrm{v})$ was used to impregnate each of the precursors for a $2 \mathrm{~h}$ period. During the activation, a $\mathrm{N}_{2}$ flow $(100 \mathrm{~mL} / \mathrm{min})$ was maintained for $2 \mathrm{~h}$ at $1173 \mathrm{~K}$ for all the precursors. Afterwards, the obtained carbon was washed with water until a neutral $\mathrm{pH}$ was observed.

\subsection{Textural Characterization of the Obtained Activated Carbon}

Textural characteristics were established through the determination of the $\mathrm{N}_{2}$ adsorption isotherms at $77 \mathrm{~K}$ and the $\mathrm{CO}_{2}$ absorption isotherms at $273 \mathrm{~K}$ in a conventional volumetric machine (Autosorb 3B, Quantachrome).

\subsection{Adsorption Equilibrium Data}

Experimental data of the adsorption equilibrium were obtained using a batch-type adsorber, which consists of a $500 \mathrm{~mL}$ Erlenmeyer flask to which $480 \mathrm{~mL}$ of a $\mathrm{Cr}(\mathrm{VI})$ solution with a known concentration was added. The $\mathrm{Cr}(\mathrm{VI})$ solution was prepared by dissolving $\mathrm{Na}_{2} \mathrm{Cr}_{2} \mathrm{O}_{7} \cdot 2 \mathrm{H}_{2} \mathrm{O}$ in solutions in which the $\mathrm{pH}$ value had previously been adjusted to the values to be evaluated $(2,4,5,6$ and 8$)$. Then the solutions were mixed with predetermined volumes of $0.01 \mathrm{M} \mathrm{HNO}_{3}$ and $0.01 \mathrm{M} \mathrm{NaOH}$.

A given mass of carbon was added to a Pyrex ${ }^{\circledR}$ glass basket specially designed and built for this experiment. Then it was placed within the adsorbent solution and was incorporated into the Erlenmeyer flask. The doses of the used activated carbon were 0.1, 0.2, 0.25, 0.5 and $1 \mathrm{~g}$, and the $\mathrm{Cr}(\mathrm{VI})$ initial concentrations varied between 5 and $120 \mathrm{mg} / \mathrm{L}$. The adsorbent was immersed in a bath under a constant temperature and the solution was stirred constantly by means of a coated stirring bar driven by a magnetic stirrer.

Carbon and $\mathrm{Cr}(\mathrm{VI})$ solutions were left in contact until an equilibrium was reached. The $\mathrm{pH}$ value of the solution was periodically measured with a $\mathrm{pH}$ meter; it was kept relatively constant by adding a solution of $0.01 \mathrm{M} \mathrm{HNO}_{3}$ and $0.01 \mathrm{M} \mathrm{NaOH}$ as required. Samples were taken several times and the $\mathrm{Cr}(\mathrm{VI})$ concentrations of each sample were determined as follows: equilibrium was considered to be reached when the concentration of $\mathrm{Cr}(\mathrm{VI})$ in two subsequent samples did not show significant variations. Preliminary experiments in our laboratory had shown that $7 \mathrm{~d}$ were sufficient to reach the equilibrium. $\mathrm{The} \mathrm{Cr}(\mathrm{VI})$ quantities were calculated by means of a mass balance.

$\mathrm{Cr}(\mathrm{VI})$ concentrations in aqueous solution were determined by means of atomic absorption spectroscopy using a Perkin-Elmer Analyst 300 machine and a calibration slope (absorbance against concentration) which was prepared with $\mathrm{Cr}(\mathrm{VI})$ standard solutions. Calibration slopes were prepared for each of the $\mathrm{pH}$ 
Table 1. Specifications of the designed model.

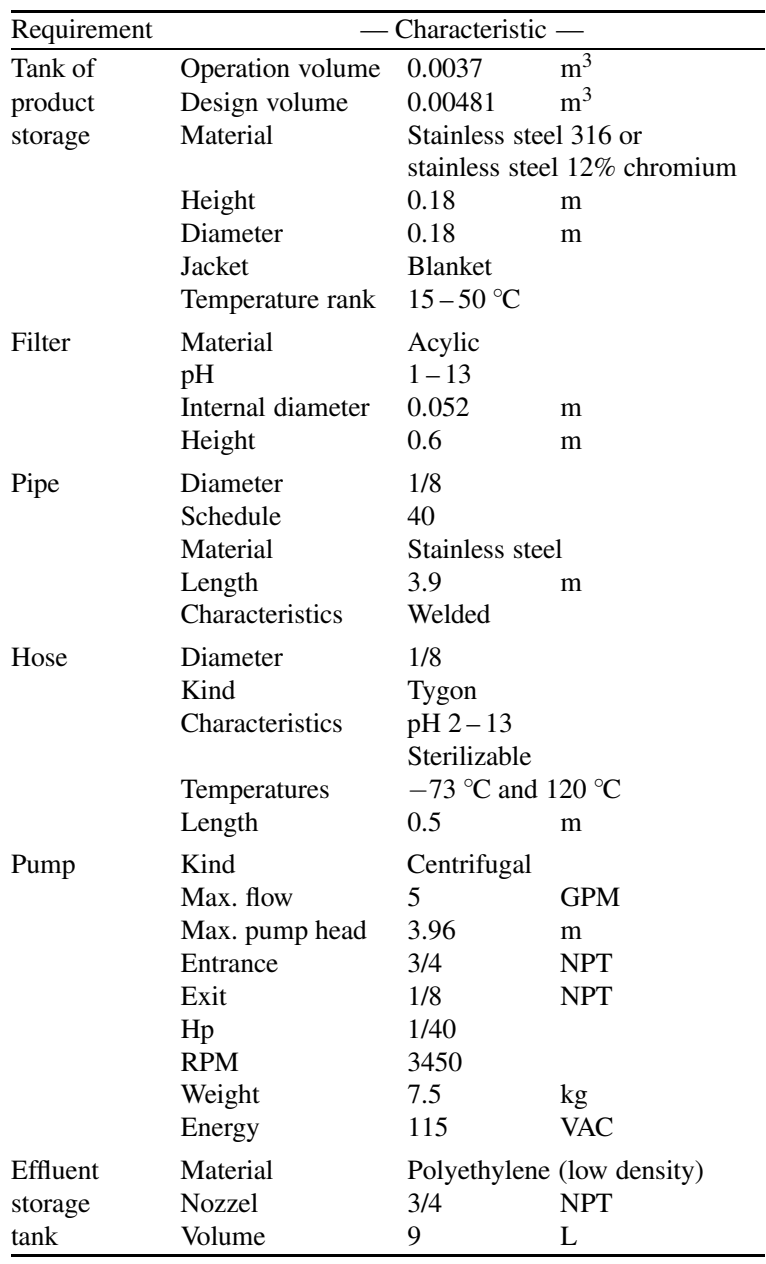

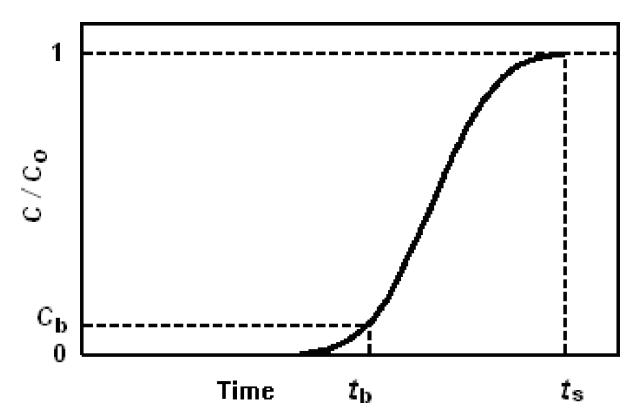

Fig. 1. Curve of breakthrough.

values tested because the slopes change with the $\mathrm{pH}$ value.

Figure 1 shows the increase of the effluent concentration with time, leading to breaking curves of the treated systems. An influent of a known concentration, which at the exit of the process had to reach a rela-

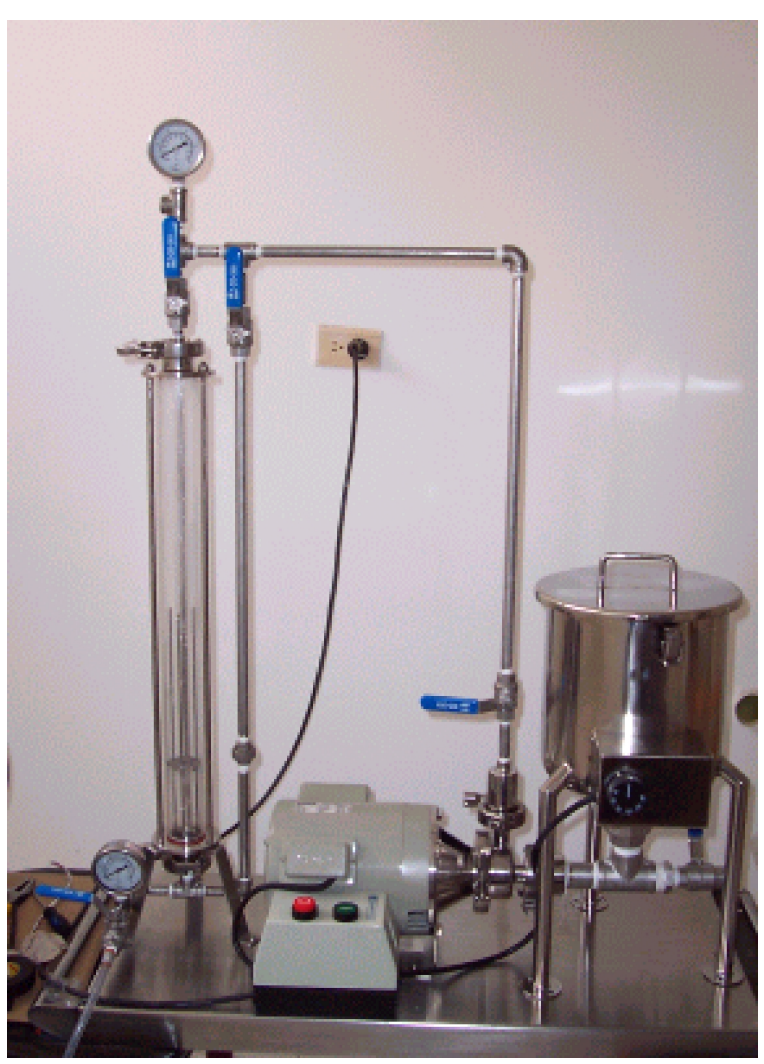

Fig. 2. Equipment for the adsorption design of a pilot plant of heavy metals.

tive concentration of 0.05 , was poured into a bed of $13 \mathrm{~cm}$ length and $0.71 \mathrm{~cm}$ diameter. This first curve, after an algebraic manipulation, was used in the scaleup process to a column of $37 \mathrm{~cm}$ length.

Using the column, a new curve was obtained simulating a system identical to the $13 \mathrm{~cm}$ column. The activated carbon had the same nature as the original, the treated solute had the same $C_{0}$. The most important parameter for the scale-up process, the velocity of the fixed bed $\left(U_{0}\right)$ was kept fixed, in order to assure a constant mass transfer zone (MTZ) and length of unused bed (LUB) in both models.

The design of the adsorption equipment at a pilot plant scale was constructed by taking into account the most important parameters for an adsorption process, with the purpose of handling all variables by changing only the operation conditions. The specifications of the model are shown in Table 1.

The storage tank for the fluid was constructed with stainless steel with chromium covering (Fig. 2), since the samples that were treated could corrode the inte- 


\begin{tabular}{lllccccc}
\hline Sample & Raw material & Activated agent & $\% \mathrm{C}$ & $\% \mathrm{~N}$ & $\% \mathrm{H}$ & $\% \mathrm{O}$ & $\%$ Ash \\
\hline CABF & Sugar cane bagasse & $\mathrm{CO}_{2}$ & 46 & 0.8 & 6.2 & 47 & 5.8 \\
CAAF & Sawdust & $\mathrm{CO}_{2}$ & 48.3 & 0.6 & 7.1 & 44 & 6.3 \\
CABQ & Sugar cane bagasse & $\mathrm{H}_{3} \mathrm{PO}_{4}$ & 39 & 1.4 & 5.1 & 54.5 & 5.1 \\
CAAQ & Sawdust & $\mathrm{H}_{3} \mathrm{PO}_{4}$ & 41 & 2.35 & 5.3 & 51.35 & 5.2 \\
\hline
\end{tabular}

Table 2. Elemental composition of the raw materials.

\begin{tabular}{llllllll}
\hline Sample Raw & Activated \% Burn & $S_{\mathrm{BET}}\left(\mathrm{m}^{2} / \mathrm{g}\right)$ & $\mathrm{N}_{2}$ at $77 \mathrm{~K}$ & \multicolumn{3}{c}{$\mathrm{CO}_{2}$ at $273 \mathrm{~K}$} \\
& material & agent & off & & $V_{0}\left(\mathrm{~cm}^{3} / \mathrm{g}\right)$ & $V_{\mathrm{T}}\left(\mathrm{cm}^{3} / \mathrm{g}\right)$ & $V_{0}\left(\mathrm{~cm}^{3} / \mathrm{g}\right)$ \\
\hline CABF & Sugar cane bagasse & $\mathrm{CO}_{2}$ & 46 & 260 & 0.321 & 0.945 & 0.124 \\
CAAF & Sawdust & $\mathrm{CO}_{2}$ & 46 & 298 & 0.456 & 0.865 & 0.157 \\
CABQ & Sugar cane bagasse & $\mathrm{H}_{3} \mathrm{PO}_{4}$ & 46 & 320 & 0.458 & 1.234 & 0.167 \\
CAAQ & Sawdust & $\mathrm{H}_{3} \mathrm{PO}_{4}$ & 46 & 367 & 0.553 & 0.987 & 0.287 \\
\hline
\end{tabular}

Table 3. Characteristics of activated carbon obtained in this work.

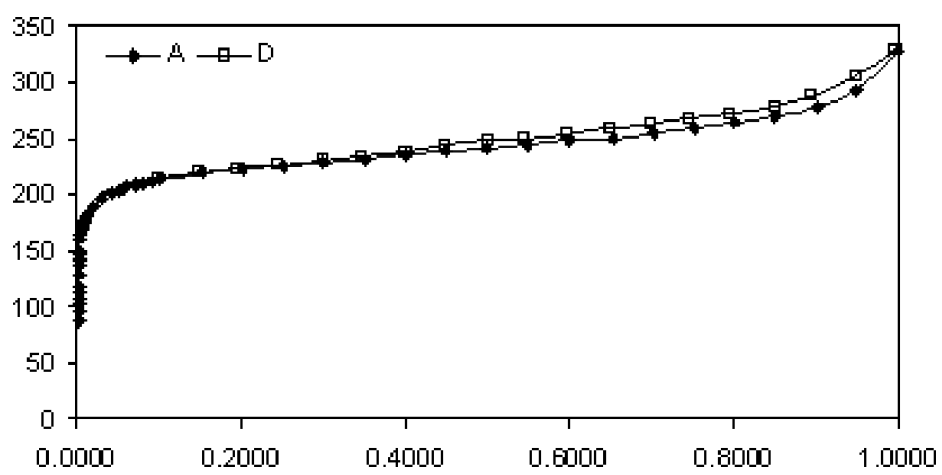

Fig. 3. Activated carbon CAAQ; A, adsorption; D, desorption.

rior of the vessel because the $\mathrm{pH}$ levels could range between 1 and 13 . In addition, the material had to sustain temperatures between 15 and $50{ }^{\circ} \mathrm{C}$, to study the effects of varying the temperature on the adsorption process. Therefore the system should have an electrical heating blanket. As a safety and stability measure, the height of the tank and the diameter are chosen to be the same.

It is necessary to use a centrifugal pump instead of a peristaltic one for filling operations because a pulsating flow would change the residence time of the liquid within the fixed bed, and it would be impossible to vary the delta pressure that produced a remarkable fluctuation of the flux. The model also needs two pressure gauges installed before and after the filter to register the pressure drop that leads to the fluid flux through the bed.

\section{Results and Discussion}

Table 2 shows the results of the elementary analysis of the initial material from which the activated carbon (CA) was subsequently obtained; each one of the materials contains a high carbon content which makes them suitable initial materials to obtain CA. The results show that the CA obtained by chemical means possesses a higher content of oxygen, owing to nitric acid oxidation which introduces oxygenated compounds (acidic, basic, and neutral) as mentioned in the literature [8-10]. Changes in the surface chemistry of a CA obtained by the formation of acidic oxygenated groups affect the behaviour of such groups when they are used as adsorbents or catalyst supporters.

In case of adsorption of inorganic compounds, such as metal ions from aqueous solution, on this type of porous solids, the nature of the surface compounds has a higher influence than the surface area and the adsorbent porosity [11 - 14]. Additionally, the effect of nitric acid on $\mathrm{CA}$ is reflected in the nitrogen content, which is more elevated in these carbon materials, probably because of the formation of nitro groups, as previously reported in the literature, or because of the irreversible adsorption of nitrate ions.

$\mathrm{N}_{2}$ adsorption isotherms at $77 \mathrm{~K}$ and those of $\mathrm{CO}_{2}$ at $273 \mathrm{~K}$ are displayed in Fig. 3, which has been adjusted to the BET model. Table 3 shows the structural parameters $V_{0}\left(\mathrm{~N}_{2}\right.$ at $\left.77 \mathrm{~K}\right), V_{\mathrm{T}}, V_{0}\left(\mathrm{CO}_{2}\right.$ at $\left.273 \mathrm{~K}\right)$, $\mathrm{BET}$ area and the burning percentage. The results show that a higher development of the surface area occurs when the CA is obtained by chemical means.

Experimental data were adjusted to the Freundlich and Langmuir isotherm models. The isotherms are 


\begin{tabular}{lccccccc}
\hline Sample & $\mathrm{pH}$ & \multicolumn{3}{c}{ Langmuir } & \multicolumn{3}{c}{ Freundlich } \\
& & $q_{\mathrm{m}}(\mathrm{mg} / \mathrm{g})$ & $K(\mathrm{~L} / \mathrm{mg})$ & $\% D$ & $k\left(\mathrm{mg}^{1-1 / n} \mathrm{~L}^{1 / n} / \mathrm{g}\right)$ & $n$ & $\% D$ \\
\hline CABFCr & 8 & 8.45 & 0.17 & 7.9 & 1.18 & 2.50 & 9.9 \\
& 6 & 16.86 & 0.07 & 6.8 & 1.26 & 1.94 & 8.4 \\
& 5 & 20.60 & 0.06 & 5.6 & 1.21 & 1.69 & 7.8 \\
& 4 & 14.55 & 0.09 & 14.6 & 1.26 & 2.33 & 16.6 \\
& 2 & 1.51 & 2.16 & 23.5 & 1.43 & 33.53 & 33.8 \\
CAAFCr & 8 & 5.65 & 0.21 & 8.2 & 1.20 & 3.72 & 12.4 \\
& 6 & 6.66 & 0.82 & 5.9 & 1.09 & 8.14 & 7.9 \\
& 5 & 8.49 & 0.70 & 4.7 & 1.09 & 6.72 & 6.7 \\
& 4 & 3.44 & 1.03 & 11.6 & 1.06 & 5.83 & 19.6 \\
& 2 & 1.94 & 8.62 & 18.9 & 1.12 & 26.36 & 38.6 \\
CABQCr & 8 & 17.11 & 0.35 & 8.9 & 1.13 & 4.31 & 10.3 \\
& 6 & 6.22 & 4.54 & 7.5 & 1.49 & 2.00 & 9.4 \\
& 5 & 67.78 & 0.22 & 6.8 & 1.20 & 3.89 & 7.4 \\
& 4 & 14.58 & 0.26 & 13.2 & 1.17 & 3.06 & 18.2 \\
& 2 & 3.97 & 5.58 & 18.2 & 1.14 & 74.90 & 24.5 \\
CAAQCr & 8 & 8.41 & 0.98 & 7.4 & 1.07 & 8.23 & 9.3 \\
& 6 & 9.50 & 1.50 & 5.9 & 1.06 & 12.33 & 6.4 \\
& 5 & 12.88 & 1.60 & 4.6 & 1.04 & 11.87 & 6.6 \\
& 4 & 4.65 & 1.66 & 14.3 & 1.04 & 8.32 & 24.8 \\
& 2 & 2.97 & 12.70 & 18.2 & 1.08 & 38.86 & 26.2 \\
\hline
\end{tabular}

Table 4. Constants of the isotherms of Langmuir and Freundlich.

mathematically represented by:

$$
\begin{aligned}
q & =\frac{q_{\mathrm{m}} K C}{1+K C}, \\
q & =k C^{1 / n},
\end{aligned}
$$

where $q(\mathrm{mg} / \mathrm{g})$ is the mass of $\mathrm{Cr}(\mathrm{VI})$ adsorbed, $C$ $(\mathrm{mg} / \mathrm{L})$ is the concentration of $\mathrm{Cr}(\mathrm{VI})$ at equilibrium, $q_{\mathrm{m}}(\mathrm{mg} / \mathrm{g})$ and $K(\mathrm{~L} / \mathrm{mg})$ are the Langmuir constants related to the maximum capacity and energy of adsorption, respectively, $k\left(\mathrm{~L}^{1 / n} \mathrm{mg}^{1-1 / n} \mathrm{~g}^{-1}\right)$ and $1 / n$ are the Freundlich constants related to the adsorption capacity and intensity, respectively.

The constants of these isotherms were evaluated by the minimum square method based on the optimization of an algorithm and are shown in Table 4 together with the absolute deviation rate, $\% D$, which is defined as

$$
\% D=\left(\frac{1}{N} \sum_{i=1}^{N}\left|\frac{q_{\exp }-q_{\mathrm{calc}}}{q_{\exp }}\right|\right) \cdot 100 \%
$$

where $N$ is the number of experimental points, $q_{\text {calc }}$ $(\mathrm{mg} / \mathrm{g})$ is the adsorbed $\mathrm{Cr}(\mathrm{VI})$ mass calculated with the isotherm model, and $q_{\text {exp }}(\mathrm{mg} / \mathrm{g})$ is the adsorbed $\mathrm{Cr}(\mathrm{VI})$ experimental mass.

The experimental values are more likely to be adjusted to the Langmuir isotherm than to the Freundlich one, and it was found that the deviation rates are lower in all the cases for the Langmuir model. In the case of the $\mathrm{Cr}(\mathrm{VI})$ ion adsorption, the lowest rates were found at $\mathrm{pH} 5$; at $\mathrm{pH}$ levels between 2 and 3 the deviations were very high with respect to other values.

The effect of the solution $\mathrm{pH}$ value on the adsorption isotherms was investigated by measuring the adsorption at the $\mathrm{Cr}(\mathrm{VI})$ equilibrium on each of the CA materials obtained at $\mathrm{pH}$ levels between 2 and 8 . Studies above $\mathrm{pH} 8$ were not performed in any of the two ion investigations, because under these conditions, they are not in their ionic states but as the precipitated species, $\mathrm{Cr}(\mathrm{OH})_{4}$ and $\mathrm{Pb}(\mathrm{OH})_{2}$.

In the chromium adsorptions, it was observed that while the adsorption took place, the $\mathrm{pH}$ value decreased and remained constant by adding a $0.01 \mathrm{M}$ $\mathrm{HNO}_{3}$ solution. This behaviour is explained by assuming that $\mathrm{H}^{+}$ions are released from the surface of $\mathrm{CA}$, whereas the lead and chromium ions in each case are adsorbed.

For example Fig. 4 shows the effect of the $\mathrm{pH}$ value on the adsorption isotherm for the physically obtained carbon materials in case of chromium ion.

According to this figure, $\mathrm{Cr}(\mathrm{VI})$ adsorption increases by a $\mathrm{pH}$ decrease and maximum adsorption occurs at $\mathrm{pH} 5$. According to the speciation diagram in the case of $\mathrm{Cr}(\mathrm{VI})$, the dominant species at $\mathrm{pH}<5$ are $\mathrm{Cr}_{2} \mathrm{O}_{7}{ }^{2-}, \mathrm{HCrO}_{4}{ }^{-}$and $\mathrm{CrO}_{4}{ }^{2-}$; in highly acid media, the surface is protonated as the adsorption of $\mathrm{Cr}(\mathrm{VI})$ is favoured in the anionic form, $\mathrm{HCrO}_{4}{ }^{-}$. With a $\mathrm{pH}$ increase, the degree of protonation of the carbon surface is gradually reduced and a decrease of the adsorption is observed. 

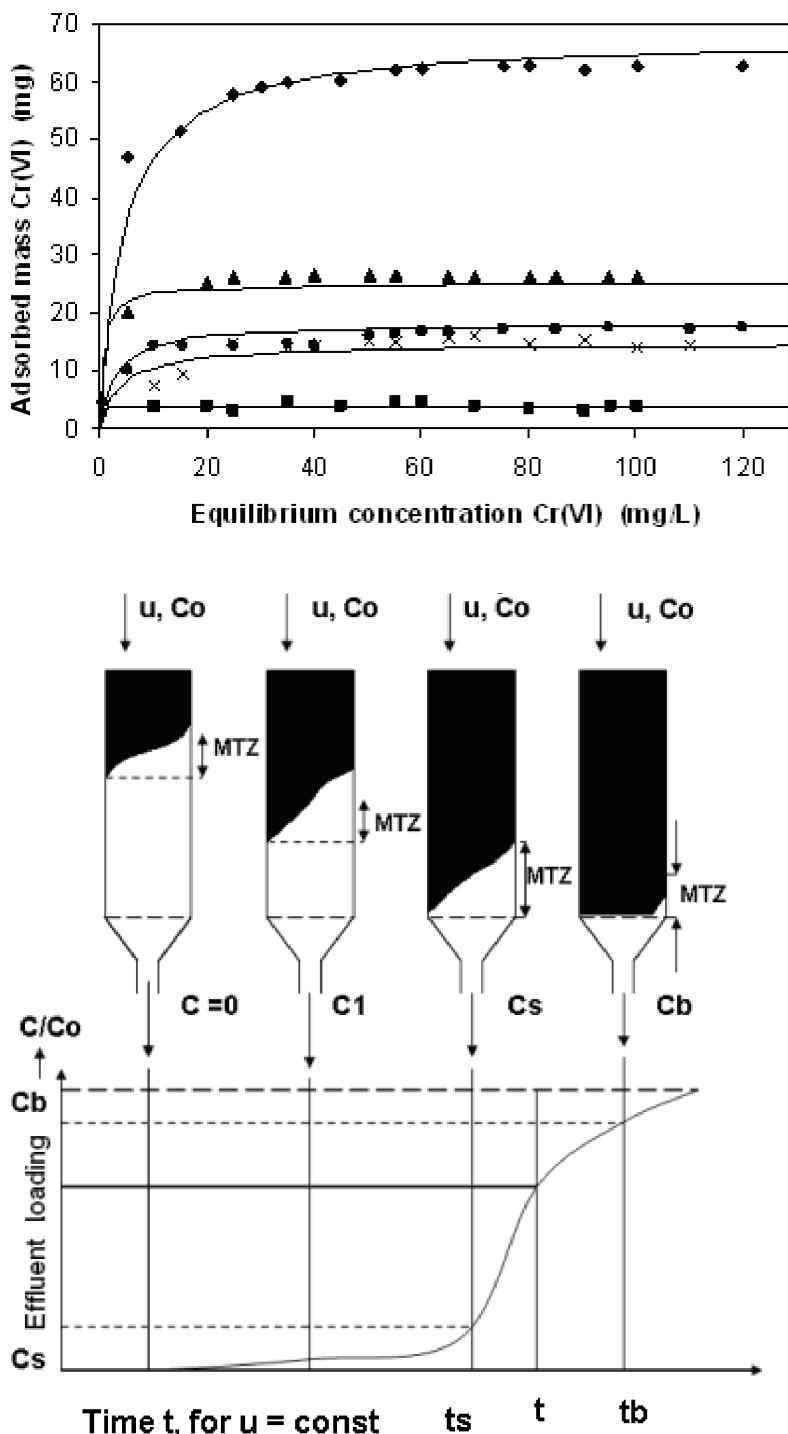

Fig. 5. The movement of the frontal adsorption zone through the bed.

Generally, the effect of the $\mathrm{pH}$ value on the adsorption isotherm is attributed to the electrostatic attractions existing between the surfaces of each of the obtained carbon materials and the $\mathrm{Cr}(\mathrm{VI})$ ions in solution.

As the carbon is saturated, the adsorption zone moves towards the inferior part of the bed; this zone is known as the mass transfer zone (MTZ) and corresponds to the stripe where the initial concentration of the influent changes until it has approached zero [4-7]. This is shown in Figure 5.

The movement of the frontal adsorption zone through the bed is obtained by means of a mass bal-

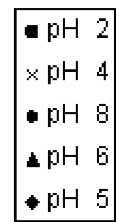

Fig. 4. pH effect on the $\mathrm{Cr}(\mathrm{VI})$ ions adsorbed onto $\mathrm{CABQCr}$.

ance:

$$
F_{\mathrm{A}}=\frac{U_{0} \cdot C_{0} \cdot \bar{M}}{\rho_{\mathrm{CA}} \cdot L}=\frac{g_{\text {solute }}}{g_{\text {adsorbent }} \cdot s},
$$

where

$$
\begin{aligned}
& U_{0}=\mathrm{cm} / \mathrm{s}, \quad C_{0}=\mathrm{mol} / \mathrm{cm}, \quad \bar{M}=g_{\text {solute }} / \mathrm{mol}, \\
& \rho_{\mathrm{b}}=g_{\text {adsorbent }} / \mathrm{cm}^{3}, \quad L=\mathrm{m} .
\end{aligned}
$$

The breakthrough curve also has certain characteristic parameters: (i) the saturation time $\left(t_{\mathrm{s}}\right)$, (ii) the capacity in the breakthrough point $\left(q_{\mathrm{b}}\right)$, (iii) the capacity at the saturation time $\left(q_{\mathrm{s}}\right)$ and (iv) $t^{*}$, being the time at which $C / C_{0}$ reaches the value of 0.5 [2], as long as the resulting curve is symmetrical as shown in Fig. $6\left(A_{1}=A_{2}\right)$.

If the curve is not symmetrical, it is difficult to measure the stoichiometric time, and a new mass balance for both areas has to be compared. It entails an iterative process to determine the exact location of $t^{*}$ established by the relation [1]

$$
\int_{0}^{t^{*}} C \mathrm{~d} t=\int_{t^{*}}^{\infty}\left(C_{0}-C\right) \mathrm{d} t, \quad A_{1}=A_{2} .
$$

The breaking $\left(t_{\mathrm{b}}\right)$ and saturation times $\left(t_{\mathrm{s}}\right)$ are calculated by means of an interpolation in the graph, but the breaking and saturation capacities are determined by integration:

$$
\begin{gathered}
q_{\mathrm{b}}=F_{\mathrm{A}} \int_{0}^{t_{\mathrm{b}}}\left(1-\frac{C}{C_{0}}\right) \mathrm{d} t=\frac{g_{\text {solute }}}{g_{\mathrm{CA}}}, \\
q_{\mathrm{s}}=F_{\mathrm{A}} \int_{0}^{\infty}\left(1-\frac{C}{C_{0}}\right) \mathrm{d} t=\frac{g_{\text {solute }}}{g_{\mathrm{CA}}} .
\end{gathered}
$$



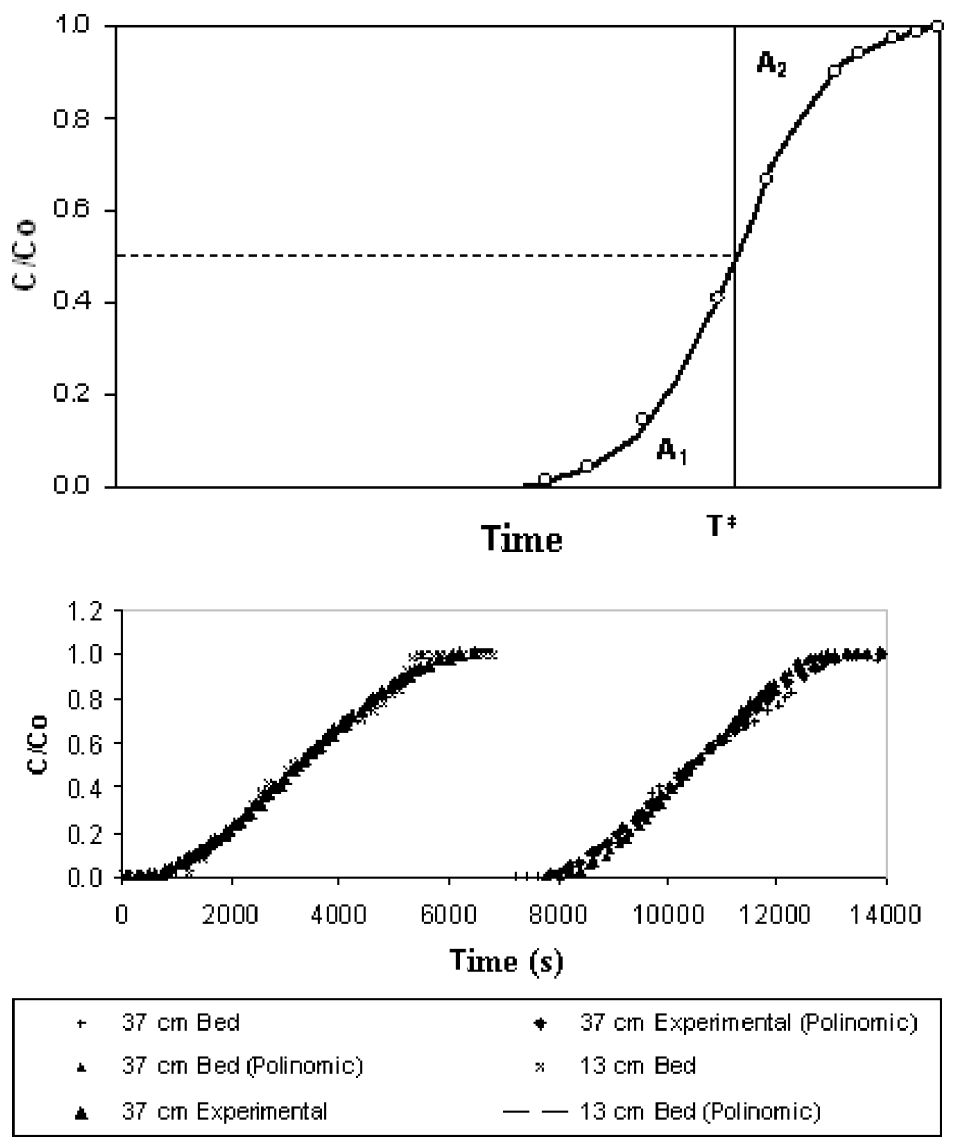

Fig. 6. The breakthrough curve for the concentration ratio versus time and its characteristic parameters.
Fig. 7. The breakthrough curve using a scaled model.
Using the curve displayed in Fig. 6, it is possible to obtain the length of unused bed (LUB), which represents the distance that is not saturated at the breaking time. The foundation of the scale-up process lies in the fact that the amount of the unused bed does not vary with the overall length of the bed, since the slope of the curve does not vary [2]. The latter is calculated as

$$
t_{\mathrm{b}}=t^{*} \cdot\left(1-\frac{\mathrm{LUB}}{L}\right) \text {. }
$$

Once the constant LUB for both models (the experimental and the scale-up one) has been obtained, and knowing the desired new length of the bed, the breaking time $\left(t_{\mathrm{b} 2}\right)$ for the column to be scaled-up is obtained using the following relation:

$$
\frac{L_{1}-\mathrm{LUB}_{1}}{t_{\mathrm{b} 1}}=\frac{L_{2}-\mathrm{LUB}_{2}}{t_{\mathrm{b} 2}}=\frac{[\mathrm{cm}]}{[\mathrm{s}]} .
$$

If we consider the units of this equation, we realize that they correspond to a velocity unit of the frontally fixed bed $\left(U_{0}\right)$, that, if kept constant during the process, should result in a nonvarying MTZ and LUB for both cases. This implies that $\mathrm{LUB}_{1}$ and $\mathrm{LUB}_{2}$ should be the same, thus being the control parameter for both models.

A possibility to maintain the velocity of the frontal bed $\left(U_{0}\right)$ constant is by using the Ergun equation [2]:

$$
\frac{\Delta p}{L}=\frac{150 U_{0} \mu(1-\varepsilon)^{2}}{\Phi_{\mathrm{s}}^{2} D_{\mathrm{p}}^{2} \varepsilon^{3}}+\frac{1.75 \rho_{\mathrm{CA}} U_{0}}{\Phi_{\mathrm{s}} D_{\mathrm{p}}}\left(\frac{1-\varepsilon}{\varepsilon^{3}}\right) .
$$

By working with the same material and the same influent it is guaranteed that the right part of (7) will be constant, with the exception of $U_{0}$. However, $U_{0}$ could be kept constant if the relation $\frac{\Delta p}{L}$ for both models is maintained. This means that when the distance of the bed is changed, the pressure drop also varies within the same relation. For our particular case, the previously described equation will be used to verify that the mathematical model is really comparable to the experimental one. 


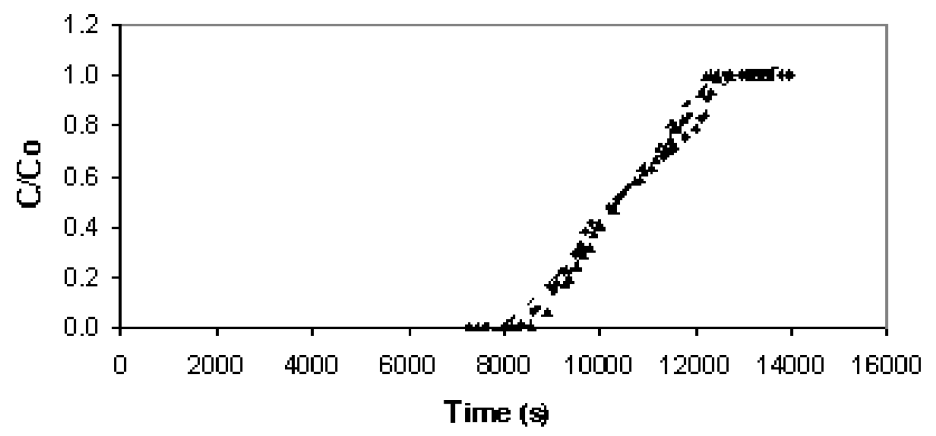

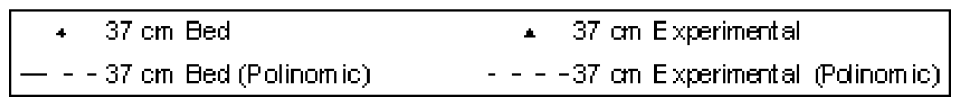

Fig. 8 . The breakthrough curve by means of an experimental model.
For the $13 \mathrm{~cm}$ length column, the calculations are the following according to Fig. 7:

$$
\begin{aligned}
t_{\mathrm{b}} & =1340.23 \mathrm{~s}, \\
t_{\mathrm{S}} & =5466.58 \mathrm{~s}, \\
F_{\mathrm{A}} & =\frac{u \cdot C_{0} \cdot \bar{M}}{\rho_{\mathrm{CA}} \cdot L} \\
& =\frac{0.125 \frac{\mathrm{cm}}{\mathrm{s}} \cdot 8465 E-8 \frac{\mathrm{mol}}{\mathrm{cm}^{3}} \cdot 207.2 \frac{g_{\text {solute }}}{\mathrm{mol}}}{0.58 \frac{\mathrm{g}}{\mathrm{cm}^{3}} \cdot 13 \mathrm{~cm}} \\
& =2.90 E-7 \frac{g_{\text {solute }}}{g_{\text {adsorbent }} \cdot s} .
\end{aligned}
$$

Therefore, the capacities at the breakthrough point and at the saturation point are as follows:

$$
\begin{aligned}
q_{\mathrm{b}} & =F_{\mathrm{A}} \int_{0}^{t_{\mathrm{b}}}\left(1-\frac{C}{C_{0}}\right) \mathrm{d} t \\
& =2.90 E-7 \int_{0}^{1340.23} 0.95 \mathrm{~d} t=3.69 E-4 \frac{g_{\text {solute }}}{g_{\mathrm{CA}}}, \\
q_{\mathrm{s}} & =F_{\mathrm{A}} \int_{0}^{\infty}\left(1-\frac{C}{C_{0}}\right) \mathrm{d} t \\
& =2.90 E-7 \int_{0}^{\infty} 0.05 \mathrm{~d} t=7.92 E-5 \frac{g_{\text {solute }}}{g_{\mathrm{CA}}} .
\end{aligned}
$$

It is clear that the capacity at the saturation point is smaller than at the breakthrough point because at this point the activated carbon is already saturated. In order to facilitate the calculation we suppose that the curve has sufficient symmetry and therefore the value of the stoichiometric time will be $t^{*}=3166.6 \mathrm{~s}$.

Manipulating (5) algebraically the value of LUB = $7.49 \mathrm{~cm}$ is obtained. In order to scale-up our model to a new column of $37 \mathrm{~cm}$ length, the values in (6) are replaced, and the breakthrough time of the new curve is obtained:

$$
t_{\mathrm{b} 2}=\frac{1340.23 \mathrm{~s}(37 \mathrm{~cm}-7.49 \mathrm{~cm})}{13 \mathrm{~cm}-7.49 \mathrm{~cm}}=7177.8 \mathrm{~s} .
$$

Once this time has been calculated, the new curve of the fixed bed can be determined by adding this value to each value of time corresponding to the first column and plotting them according to the same relative concentrations.

As is shown in Fig. 8, the experimental model of $37 \mathrm{~cm}$ is very similar to the one obtained by means of the scale-up; this agreement of both models was obtained by reproducing the experimental models that were realized, trying to always work with the same material and maintaining a constant relation $\frac{\Delta p}{L}$ in order to obtain the same flow velocity. In addition if we compare the LUB values by using (5) for both beds of $37 \mathrm{~cm}$, the experimental curve does not give a significant deviation (4.6\%), since it has an LUB value of $7.15 \mathrm{~cm}$ and, within the experimental error, the lengths of unused bed are congruent.

\section{Conclusions}

Activated carbon obtained by the chemical method shows a higher adsorption capacity with respect to chromium ions. Chemical treatment with nitric acid proved to generate a higher content of acid groups on the carbon surface. This is the reason why, at the studied $\mathrm{pH}$ levels, the ions showed a high adsorption capacity.

The solution $\mathrm{pH}$ value plays an important role in $\mathrm{Cr}(\mathrm{VI})$ ion adsorption. The highest adsorption capac- 
ity was at $\mathrm{pH} 4$ and 5 , respectively, with a tendency to increase the $\mathrm{pH}$ value during ion adsorption, owing to the hydrolysis of carboxylic groups at higher $\mathrm{pH}$ levels.

In this project a simple and applicable model was proposed. It provides an interesting approach to industrial models through experimental data obtained from fixed bed adsorption columns. The proposed method does not require intricate calculations, use of correlations, nor to determine any type of coefficients, which makes it a model near to reality as long as the reproducibility of the system under consideration could be guaranteed; this means that the adsorption phenomenon must guarantee constant design parameters, as (i) activated carbon used for the fixed bed, (ii) the nature of the influent and (iii) the superficial velocity of the system that maintains the retention time fixed.

The use of this process in an industrial scale-up design caused by the existing relationship between both models, having the same LUB. It is important to mention that the same pressure drop is fixed for both the experimental model and the industrial one by keeping

[1] M. C. Basso, E. G. Cerrella, and A. L. Cukierman, Programa de Investigación y Desarrollo de Fuentes Alternativas de Materias Primas y Energía - PINMATE, Departamento de Industrias, Facultad de Ciencias Exactas y Naturales, Universidad de Buenos Aires 1996.

[2] J. Blanco, P. R. Castro, and E. G. Bonelli, Activación química de bagazo de caña de azúcar para la obtención de carbones activados. Programa de Investigación de Fuentes Alternativas de Materias Primas y Energía (PINMATE), Departamento de Industrias, Facultad de Ciencias Exactas y Naturales, Universidad de Buenos Aires 1996.

[3] J. Hayashi and K. Atsuo, Carbon 38, 1873 (2000).

[4] M. Kobya, Biores. Technol. 40, 317 (2004).

[5] H. Marsh, A. Heintz, and F. Rodriguez-Reinoso, Introduction to Carbon Technologies, Chapter 2, Universidad de Alicante, Secretariado de Publicaciones 1998. a constant MTZ. Otherwise the slopes of the curves will vary and this will change the characteristic times of the plots and therefore all the calculations.

The results shown above can be used as a practical tool for designing industrial absorbers because of the simplicity and accuracy which the modelling of a fixed bed offers.

\section{Acknowledgements}

This project was supported by CIFI (Engineering Faculty Investigation Centre, acronym CIFI in Spanish) and the Sciences Faculty Research Group, both centres belonging to the Universidad de Los Andes (Colombia). We extend our special thanks to the Chemistry Faculty and its team for being extremely supportive and dedicated. In addition, the authors thank the Departments of Chemistry of the Universidad Nacional de Colombia and Universidad de Los Andes and the frame agreement established between these two institutions.

[6] Y. Shaobin, Carbon 40, 277 (2002).

[7] A. M. Tolmachev, Carbon 40, 1401 (2002).

[8] Z. Reddad, C. Gérente, Y. Andrès, and P. Le Cloirec, Environ. Sci. Technol. 36, 2242 (2002).

[9] M. Mitchell, E. Wayne, A. Marshall, A. Christopher, and A. Toles, J. Chem. Technol. Biotechnol. 71, 131 (1998).

[10] Z. Reddad, C. Gérente, Y. Andrès, and P. Le Cloirec, Environ. Sci. Technol. 36, 2067 (2002).

[11] S. Al-Asheh and F. Banat, Adsorption Sci. Technol. 18, 685 (2000).

[12] V. Trivette, W. Chung, E. Seo, and E. Wayne, Biores. Technol. 78, 133 (2001).

[13] J. W. Kim, M. H. Sohn, D. S. Kim, S. M. Sohn, and Y. S. Kwon, J. Hazardous Mat. 85, 301 (2001).

[14] Y. Nevin, S. Vahdettin, Carbon 38, 1943 (2000). 